\title{
RETRACTED ARTICLE: Enhancing the LTE-Based Intelligent Transportation System's Performance
}

\author{
Omar R. Daoud ${ }^{1}$ - Qadri J. Hamarsheh ${ }^{2} \cdot$ Ahlam A. Damati $^{3}$
}

Accepted: 14 September 2020 / Published online: 24 September 2020

(c) Springer Science+Business Media, LLC, part of Springer Nature 2020

The Editor-in-Chief has retracted this article due to significant overlap with a previously published article by the same authors [1].

All authors agree to this retraction. The online version of this article contains the full text of the retracted article as Supplementary Information.

Supplementary Information The online version contains supplementary material available at https://doi. org/10.1007/s11277-020-07845-7.

\section{References}

1. Daoud, O., Hamarsheh, Q., \& Damati, A. (2020). Enhancing the LTE-based intelligent transportation system's performance. Digital Signal Processing, 99, 102677. https://doi.org/10.1016/j. dsp.2020.102677.

Omar R. Daoud

odaoud@philadelphia.edu.jo

Qadri J. Hamarsheh

qhamarsheh@phladephia.edu.jo

Ahlam A. Damati

adamati@philadelphia.edu.jo

1 Department of Communications and Electronics Engineering, Faculty of Engineering and Technology, Philadelphia University, Amman 19392, Jordan

2 Department of Computer Engineering, Faculty of Engineering and Technology, Philadelphia University, Amman 19392, Jordan

3 Department of Electrical Engineering, Faculty of Engineering and Technology, Philadelphia University, Amman 19392, Jordan 